\title{
BMJ Open Healthcare utilisation of patients with cholecystolithiasis in primary care: a multipractice comparative analysis
}

\author{
Floris Martijn Thunnissen (D , ${ }^{1}$ Luuk David Drager, ${ }^{1}$ Breg Braak, ${ }^{2}$ Joost P H Drenth, ${ }^{3}$ \\ Cornelis J H M van Laarhoven, ${ }^{1}$ Henk J Schers (I) ,2 ${ }^{2}$ Philip R de Reuver ${ }^{1}$
}

To cite: Thunnissen FM, Drager LD, Braak B, et al. Healthcare utilisation of patients with cholecystolithiasis in primary care: a multipractice comparative analysis. BMJ Open 2021;11:e053188. doi:10.1136/ bmjopen-2021-053188

- Prepublication history and additional supplemental material for this paper are available online. To view these files, please visit the journal online (http://dx.doi.org/10.1136/ bmjopen-2021-053188).

FMT and LDD contributed equally.

Received 06 May 2021 Accepted 21 October 202

Check for updates

(C) Author(s) (or their employer(s)) 2021. Re-use permitted under CC BY-NC. No commercial re-use. See rights and permissions. Published by BMJ.

${ }^{1}$ Surgery, Radboudumc, Nijmegen, The Netherlands ${ }^{2}$ Primary and Community Care, Radboudumc, Nijmegen, The Netherlands

${ }^{3}$ Gastroenterology, Radboudumc, Nijmegen, The Netherlands

Correspondence to

Dr Philip R de Reuver;

philip.dereuver@radboudumc.nl

\section{ABSTRACT}

Objectives To examine general practitioners' (GP) management of cholecystolithiasis and to evaluate persisting abdominal complaints in the years after the diagnosis.

Design Retrospective analysis of registry data and a subset of individual medical records.

Setting Seventeen primary care practices affiliated with the Radboudumc Practice Based Research Network in the Netherlands.

Participants 633 patients with cholecystolithiasis diagnosed between 2012 and 2016.

Primary and secondary outcome measures The primary outcome of this study was the healthcare utilisation of patients with cholecystolithiasis diagnosed by the GP in terms of referrals to secondary care, laboratory diagnostics, prescribed medication and the prevalence of concomitant abdominal-related diagnoses in a time interval of 3 years before and 3 years after diagnosis of cholecystolithiasis. For secondary outcomes, electronic medical records were studied from seven practices to assess emergency department visits, operation rates and repeat visits for persistent abdominal symptoms. We compared the non-referred group with the referred group. Results In $57 \%$ of patients, concomitant abdominalrelated diagnoses were recorded besides the diagnosis cholecystolithiasis. In-depth analyses of 294 patients showed a referral rate of $79.3 \%(n=233) ; 62.9 \%(n=185)$ underwent cholecystectomy. After referral, 55.4\% (129/233) returned to the GP for persistent abdominal symptoms. Patients returning after referral were more often treated for another abdominal-related diagnosis before cholecystolithiasis was recorded $(51.9 \%$ vs $28.8 \%$, $\mathrm{p}<0.001$ ).

Conclusions The majority of patients in general practice with gallstones are referred and undergo cholecystectomy. Patients with concomitant abdominal-related diagnoses are likely to return to their physician. GPs should inform patients about these outcomes to improve the shared decision-making process before gallbladder surgery.

\section{INTRODUCTION}

Cholecystolithiasis constitutes a significant and growing health problem in an increasingly obese population. Annually, Dutch hospital registrations record over 30000 patients diagnosed with cholecystolithiasis, of

\section{Strengths and limitations of this study}

First study addressing treatment and outcomes of cholecystolithiasis in primary care.

- The entire workup and follow-up of patients with cholecystolithiasis was considered by the 6 years time interval, 3 years before and 3 years after the diagnosis of cholecystolithiasis.

- Although retrospective, the use of electronic medical records ensure complete information.

- This study only examines a primary care perspective and does not explore subsequent treatment trajectories between medical specialists.

whom $75 \%$ undergo surgery. In the USA, over 300000 cholecystectomies are performed per year. ${ }^{1}$ There is clear consensus that cholecystectomy is indicated for patients who develop biliary complications such as cholecystitis and biliary pancreatitis. The indication is less clear for patients who present with cholecystolithiasis and abdominal pain. ${ }^{2-4}$

A recent clinical trial (SECURE-trial) addressed the lack of consensus on the indication for surgery for uncomplicated cholecystolithiasis. This trial randomised 1067 patients to usual care or a restrictive policy in which surgery was only performed after strict diagnostic criteria were met. ${ }^{5}$ After 1-year follow-up, $40 \%$ of the patients suffered from persistent abdominal pain regardless the study arm. A possible explanation is that many patients with cholecystolithiasis and abdominal pain have features of functional gastrointestinal disorders, and this category in particular had a higher risk of persistent postoperative pain. ${ }^{6}$ The mediocre outcome of cholecystectomy supports the need for better patient selection for surgery and to better inform patients in order to manage expectations.

The information on the outcome of treatment for cholecystolithiasis patients is to a large extent derived from studies with a 
secondary care perspective. Little is known on the diagnostic care pathway of patients with cholecystolithiasis within primary care. For this study, we collected clinical data of patients diagnosed with cholecystolithiasis in primary care and assessed their healthcare utilisation, presence of other abdominal-related diagnoses, and outcome of referral to secondary care. The purpose was to evaluate the outcomes of treatment for referred and non-referred patients, and second to determine differences in patients with and without cholecystectomy.

\section{METHODS}

\section{Setting}

We analysed registry data from 17 general practices affiliated with the Radboud University Medical Centre Practice Based Research Network in Nijmegen, the Netherlands. Subsequently, for in-depth analysis, we studied data from the medical records in a subset of seven affiliated practices. These practices were elected for feasibility purposes. Registry data extraction was performed by the Radboudumc Technology Centre Health Data (department for Primary and Community care), which provides support for extraction and secure storage of routine data. Informed consent from individual patients for a retrospective study with anonymised patient data is not mandatory under Dutch Law. We used the Strengthening the Reporting of Observational Studies in Epidemiology cohort checklist when writing our report. ${ }^{7}$

\section{Study population and patient selection}

Patients were eligible for inclusion if aged 18 years and older and diagnosed with cholecystolithiasis between January 2012 and December 2016. Diagnosis was defined by the International Classification of Primary Care (ICPC), which allows categorisation of data in an episode of care structure. Patients were only eligible for inclusion if they were registered with their general practitioner (GP) at least 3 years prior and 3 years after the diagnosis cholecystolithiasis. This selection resulted in a complete time interval of 6 years to assess the diagnostic pathway, referral pattern and follow-up.

\section{Variables and outcomes}

For the primary outcome, we studied healthcare utilisation in the registry data. Healthcare utilisations was defined as laboratory diagnostics and prescribed medication for 6 years, 3 years leading up to the diagnosis of cholecystolithiasis plus 3 years of follow-up. Additionally, we assessed the number of recorded abdominal-related diagnoses (eg, abdominal pain, stomach-ache, acidrelated disease, constipation, irritable bowel syndrome) within the same time frame, according to the registered ICPC codes (for details on collected registry data see online supplemental table S1).

For the secondary outcomes, the following data was extracted from the electronic medical records (EMRs) of individual patients: age, sex, body mass index (BMI), abdominal symptoms, presence of biliary colic, cholecystolithiasis on abdominal imaging (ultrasound, CT or MR cholangiopancreatography), department specific referral, time interval between diagnosis and referral, acute biliary presentations in the emergency department (ED) and cholecystectomy. In referred patients, the number of repeat visits due to persistent abdominal symptoms and newly recorded abdominal pain-related diagnoses were assessed (for details on collected individual patient data see online supplemental table S2). Complaints recorded within 6 weeks of surgery were considered to be surgery related and were not scored.

\section{Definitions for primary care treatment, referral and patients returning after referral}

Initial treatment was defined as treatment by the GP (eg, wait-and-see policy with lifestyle advice or prescription of medication), or referral to secondary care with corresponding treatment. Referred patients were defined as patients who visited the hospital outpatient clinic of the department of surgery, gastroenterology or presented to the ED which was documented in the patient medical file. Patients treated in ED were regarded as patients with an acute biliary presentation (due to severe biliary colic, cholecystitis or biliary pancreatitis). Patients who were referred to another medical specialist or were only treated by the GP were considered as non-referred patients. Patients who returned to their GP for abdominal-related complaints after referral were considered as returning patients.

\section{Comparison of patients with different treatment trajectories}

Different patient groups were compared with assess characteristics or symptoms associated with referral and cholecystectomy. Patients with and without referral and patients with and without cholecystectomy were compared. Second, differences in treatment outcomes were determined between these groups regarding the number of patients returning for persistent abdominal symptoms.

\section{Patient and public involvement \\ No patient involved.}

\section{Statistical analyses}

Descriptive statistics were used to summarise baseline characteristics. Continuous variables were presented as mean with SD in case of normally distributed data and median with IQR for skewed data. Categorical variables were compared using the $\chi^{2}$ test, and continuous data were compared using unpaired t-tests for normally distributed data or Mann-Whitney U tests for skewed data. To determine whether the individual patients were comparable in terms of age, gender and BMI to the registry cohort, these variables were tested for a significant difference. A $p<0.05$ indicated statistical significance. All statistical analyses were performed in IBM SPSS Statistics Software, V.25. 


\section{Typical patient with cholecystolithiasis treated in primary care}

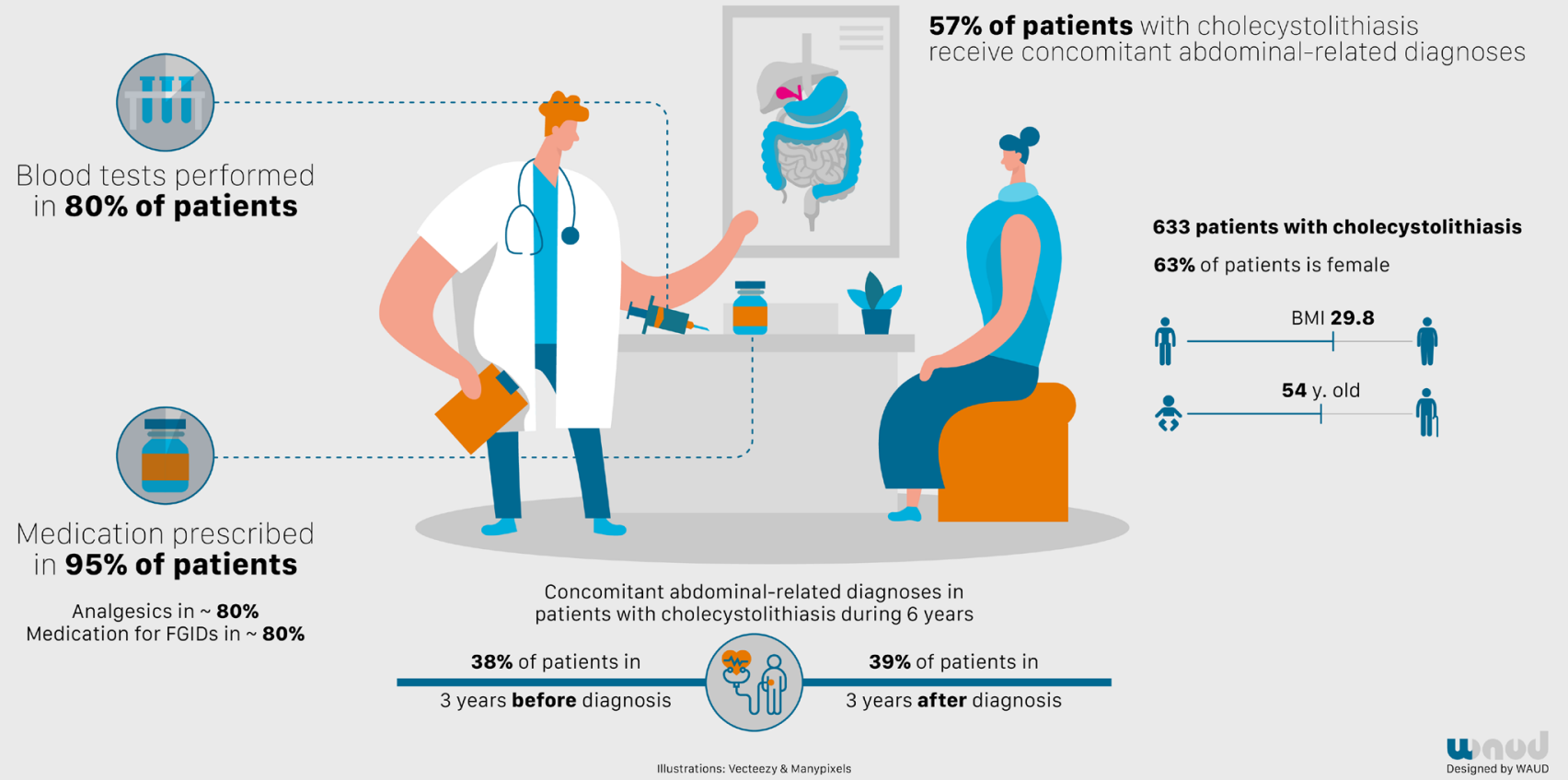

Figure 1 Typical patient with cholecystolithiasis treated in primary care. Registry data from 633 patients. BMI, body mass index.

\section{RESULTS}

\section{Patients}

After exclusion of 6 patients under 18 years of age, a total of 633 patients from 17 practices were included in the registry analysis. For the in-depth analysis, 7 general practices from the network also provided data from medical files of 294 patients.

\section{Registry data: the typical patient with cholecystolithiasis treated in primary care}

Analysis of the registry data resulted in an infographic illustrating the typical patient with cholecystolithiasis treated in primary care (figure 1). The mean age at the time of the diagnosis of cholecystolithiasis was 54.7 years. Male:female ratio was 1:1.6 and the mean BMI was 29.8 $\mathrm{kg} / \mathrm{m}^{2}$. Liver function tests were performed in 511 out of 633 patients $(80.7 \%)$. Medication was prescribed in $95 \%$ of patients. Most commonly prescribed medication were NSAIDs $(83.5 \%)$, medication for gastric disease $(79.5 \%)$ and other analgesics $(61.3 \%)$.

During 6 years, concomitant abdominal-related diagnoses were recorded in $56.9 \%$ of patients. Most frequent recorded ICPC-codes were abdominal pain (30.5\%), stomach ache (13.7\%), constipation (10.6\%) and acidrelated disease $(10.0 \%)$.

Patients with cholecystolithiasis: characteristics, referral patterns, operation rates and patients returning after referral The medical files of 294 patients with cholecystolithiasis showed similar characteristics to the registry cohort in terms of age, sex and BMI (53.7 vs 54.7 years, $\mathrm{p}=0.36$;
$63.6 \%$ vs $63 \%$ female, $\mathrm{p}=0.67$; and $29.5 \mathrm{~kg} / \mathrm{m}^{2}$ vs 29.8 $\mathrm{kg} / \mathrm{m} 2, \mathrm{p}=0.91$, respectively). GPs documented the presence of a biliary colic in $57.5 \%$ of patients $(169 / 294)$. Cholecystolithiasis was confirmed by imaging in 227 patients $(77.5 \%)$. Two hundred and thirty-three patients $(79.3 \%)$ were referred and $62.9 \%(\mathrm{n}=185)$ underwent cholecystectomy. Patients were primarily referred to the surgery, gastroenterology or ED, in $42.5 \%, 10.3 \%$ and $47.2 \%$, respectively. The median time interval between diagnosis and referral was 9 days (IQR 43). Figure 2 illustrates the differences in referral rate, referral location and the median time interval in weeks between the diagnosis and referral per primary care facility. No significant differences were observed in terms of referral rate and time interval to referral between the facilities.

After initial treatment, GPs recorded persistent abdominal symptoms in $52.4 \%$ of patients $(\mathrm{n}=154)$. Pain $(38.4 \%)$ was the most commonly recorded diagnosis, followed by diarrhoea $(6.8 \%)$.

\section{Comparison of patients with and without referral}

Patients with referral did not differ from patients without referral in terms of age, sex, BMI, frequency of blood tests, and prescribed medication (table 1). GPs were more likely to refer patients to the hospital if a biliary colic was recorded $(61.8 \%$ vs $41.0 \%, \mathrm{p}=0.003)$. Moreover, during 6 years, referred patients more often visited their GP for abdominal symptoms (median 9 (IQR 8) vs 6 (IQR 6), $\mathrm{p}<0.001)$. 


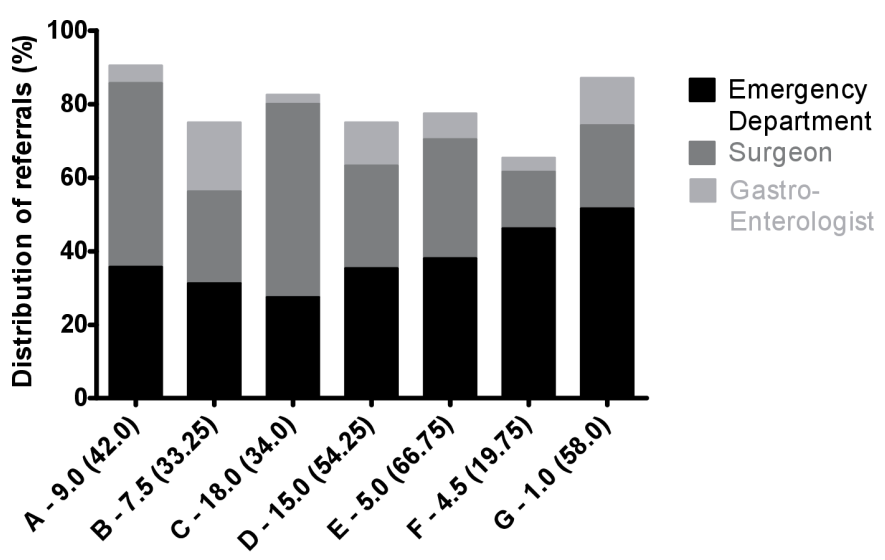

General Practice - Time to referral in days (IQR)

Figure 2 Difference in referral rate, location and time interval between diagnosis and referral among seven primary care practices $(A-G)$. No significant difference was observed in the referral rate $(p=0.19)$ or time interval $(p=0.60)$ between diagnosis and referral among seven primary care practices.

During a follow-up after the diagnosis cholecystolithiasis, persistent symptoms were more often recorded in referred patients compared with patients without a referral $(55.4 \%$ vs $41 \%, \mathrm{p}=0.045)$. Referred patients more often received an additional abdominal-related diagnosis after the diagnosis of cholecystolithiasis compared with non-referred patients $(48.9 \%$ vs $34.4 \%, \mathrm{p}<0.001)$. During a follow-up, $24 \%(56 / 233)$ of previously referred patients were referred to secondary care for a second time due to persistent abdominal symptoms.

\section{Acute biliary presentations}

One hundred and ten patients $(47.2 \%)$ were referred to the ED with an acute biliary presentation. No significant difference was observed between patients presented to ED versus patients referred to other departments in terms of age, sex and BMI. After presentation in ED, with or without cholecystectomy, these patients recorded similar persistent symptoms and frequency of repeat GP visits compared with patients without a presentation in ED.

\section{Comparison of patients with and without cholecystectomy}

Cholecystectomised patients were younger ( 53.1 vs 57.7 years, $p=0.045$ ), their initial referral was more often to the department of surgery $(49.2 \%$ vs $16.7 \%$, $\mathrm{p}<0.001)$ and less to the department of gastroenterology $(7.6 \%$ vs $20.8 \%$, $\mathrm{p}<0.001)$ or the ED $(43.2 \%$ vs $62.5 \%, \mathrm{p}<0.001)$. Less patients who underwent cholecystectomy reported pain during a follow-up (36.2\% vs $60.4 \%, \mathrm{p}=0.002)$ (table 1$)$.

\section{Outcome after referral}

After referral, 55.4\% of patients consulted their GP for persistent abdominal symptoms. Patients who return to their GP for persistent abdominal symptoms after referral were more often diagnosed with concomitant abdominal-related diagnoses prior to the diagnosis of cholecystolithiasis $(51.9 \%$ vs $28.8 \%, \mathrm{p}<0.001)$. Returning patients also visited their GP more often before the diagnosis of cholecystolithiasis (3 (IQR 3) vs 2 (IQR 2), $\mathrm{p}<0.001$ ) (table 2). A biliary colic was less often reported in returning patients $(55.8 \%$ vs $69.2 \%, \mathrm{p}=0.04)$.

\section{DISCUSSION}

\section{Summary}

During 6 years of follow-up, liver function tests were performed in $81 \%$ of patients and medication was prescribed in $95 \%$ of patients. More than half of the patients referred for the treatment of cholecystolithiasis return to their GP for persistent abdominal symptoms irrespective of cholecystectomy. Patients with previous abdominal-related diagnoses are more likely to return after referral compared with patients without other initial diagnoses. Pre-existent abdominal-related symptoms are a major cause of persistent symptoms after cholecystectomy, and GPs should be aware about these suboptimal outcomes of referral to secondary care.

We found that liver function tests were performed in $81 \%$ of patients, while international guidelines do not advocate the use of laboratory tests in patients with uncomplicated cholecystolithiasis because they do not contribute to the diagnosis. ${ }^{8}$ We also found that medication was prescribed in $95 \%$ of patients and NSAIDs were the most commonly prescribed drug. This is good practice, as a typical biliary colic should respond to simple analgesics. $^{8}$

Persistent abdominal symptoms after cholecystectomy are a clinical dilemma and are accompanied by a significant burden for patient and healthcare system. ${ }^{9}$ Causes for persisting pain relate to surgery, residual gallstones or undiagnosed alternative functional gastrointestinal disorders. ${ }^{50-12}$ The outcome of this study in a primary care setting is in line with existing surgical literature reporting persistent postoperative pain in $40 \%$ of patients. Analysis of the SECURE-trial, a recent randomised controlled trial designed to compare the conventional indication for cholecystectomy with a more restrictive and criteriabased strategy in patients with abdominal pain and ultrasound-proven gallstones, showed that the Rome III criteria (severe steady pain, lasting $30 \mathrm{~min}$, located in the epigastrium and/or right upper quadrant) have limited validity in the selection of patients for cholecystectomy as these criteria are poorly associated with a postoperative pain-free state. ${ }^{5}$ Selection of patients with uncomplicated cholecystolithiasis for referral for surgery is just as challenging. Previous studies have shown that a proportion of patients with uncomplicated cholecystolithiasis who are initially treated conservatively, may never require surgery. ${ }^{9}$ There is an ongoing clinical trial in the UK that aims to randomise 430 patients to evaluate conservative medical management and cholecystectomy in terms of quality of life and cost-effectiveness. ${ }^{13}$ The background for this trial are two Norwegian studies which suggest that conservative management may be a safe alternative to surgery in selected patients. About 55\% of the 201 patients randomised to conservative management in these trials 
Table 1 Characteristics and outcomes of patients with and without referral and with and without cholecystectomy

\begin{tabular}{|c|c|c|c|c|c|}
\hline & \multirow[b]{2}{*}{$\begin{array}{l}\text { All patients } \\
(\mathrm{N}=294)\end{array}$} & \multirow[b]{2}{*}{$\begin{array}{l}\text { Referral } \\
(\mathrm{N}=233)\end{array}$} & \multirow[b]{2}{*}{$\begin{array}{l}\text { No referral } \\
(\mathrm{N}=61)\end{array}$} & \multicolumn{2}{|l|}{ Referral } \\
\hline & & & & $\begin{array}{l}\text { Cholecystectomy } \\
(\mathrm{N}=185)\end{array}$ & $\begin{array}{l}\text { No cholecystectomy } \\
(\mathrm{N}=48)\end{array}$ \\
\hline Age, mean (SD) & $53.7(14.2)$ & $54.1(14.0)$ & $52.4(15.1)$ & $53.1(14.2)$ & $57.7(12.9)^{\star}$ \\
\hline Sex, female (\%) & $187(63.6)$ & $147(63.1)$ & $40(65.6)$ & $122(65.9)$ & $25(52.1)$ \\
\hline $\begin{array}{l}\text { BMl in } \mathrm{kg} / \mathrm{m}^{2}, \text { mean } \\
\text { (SD) } \dagger\end{array}$ & $29.5(5.7)$ & $29.7(5.7)$ & $28.5(5.8)$ & $30.0(6.5)$ & $28.9(4.7)$ \\
\hline $\begin{array}{l}\text { Concomitant abdominal- } \\
\text { related diagnosis, } \mathrm{n}(\%)\end{array}$ & $182(61.9)$ & $148(63.5)$ & $34(55.7)$ & $117(63.2)$ & $31(63.5)$ \\
\hline $\begin{array}{l}\text { Before diagnosis } \\
\text { cholecystolithiasis }\end{array}$ & $116(39.5)$ & 93 (39.9) & $23(37.7)$ & $74(40.0)$ & $19(39.6)$ \\
\hline $\begin{array}{l}\text { After diagnosis } \\
\text { cholecystolithiasis }\end{array}$ & $135(45.9)$ & $114(48.9)$ & 21 (34.4)‡ & $89(48.1)$ & $25(52.1)$ \\
\hline $\begin{array}{l}\text { No of consultations } \\
\text { related to } \\
\text { cholecystolithiasis } \\
\text { or abdominal-related } \\
\text { diagnoses, median (IQR) }\end{array}$ & $8(9)$ & $9(8)$ & 6 (6)‡ & $9(8)$ & $11.5(11.75)$ \\
\hline $\begin{array}{l}\text { Before diagnosis of } \\
\text { cholecystolithiasis }\end{array}$ & $3(3)$ & $3(3)$ & 2 (2)‡ & $3(3)$ & $3(4)$ \\
\hline $\begin{array}{l}\text { After diagnosis } \\
\text { cholecystolithiasis\$ }\end{array}$ & $6(6)$ & $6(6)$ & 4 (5)‡ & $6(6)$ & $6.5(9)$ \\
\hline Biliary colic, n (\%) & $169(57.5)$ & $144(61.8)$ & $25(41.0) \ddagger$ & $119(64.3)$ & 25 (52.1) \\
\hline $\begin{array}{l}\text { Referral to secondary } \\
\text { care, } \mathrm{n}(\%)\end{array}$ & $233(79.3)$ & $233(100)$ & $\mathrm{N} / \mathrm{A}$ & $185(100)$ & $48(100)$ \\
\hline Dept. of surgery & & $99(42.5)$ & $\mathrm{N} / \mathrm{A}$ & $91(49.2)$ & $8(16.7)^{\star}$ \\
\hline $\begin{array}{l}\text { Dept. of } \\
\text { gastroenterology }\end{array}$ & & $24(10.3)$ & $\mathrm{N} / \mathrm{A}$ & $14(7.6)$ & $10(20.8)^{\star}$ \\
\hline $\begin{array}{l}\text { Emergency } \\
\text { department }\end{array}$ & & $110(47.2)$ & $\mathrm{N} / \mathrm{A}$ & $80(43.2)$ & $30(62.5)^{\star}$ \\
\hline $\begin{array}{l}\text { Time interval between } \\
\text { diagnosis and referral in } \\
\text { days, median (IQR) }\end{array}$ & $9(43)$ & $9(43)$ & N/A & $9(42)$ & $8(72.25)$ \\
\hline $\begin{array}{l}\text { GP consultation for } \\
\text { persistent abdominal } \\
\text { symptoms after initial } \\
\text { treatment, } \mathrm{n}(\%)\end{array}$ & $154(52.4)$ & $129(55.4)$ & 25 (41.0)‡ & $97(52.4)$ & $32(66.7)$ \\
\hline \multicolumn{6}{|l|}{ Type of symptoms } \\
\hline Pain & $113(38.4)$ & 96 (41.2) & $17(27.9)$ & 67 (36.2) & $29(60.4)^{\star}$ \\
\hline Heartburn & $12(4.1)$ & $6(2.6)$ & 6 (9.8)‡ & $6(3.2)$ & $0(0)$ \\
\hline Diarrhoea & $20(6.8)$ & $19(8.2)$ & $1(1.6)$ & $16(8.6)$ & $3(6.3)$ \\
\hline Other & $9(3.1)$ & $8(3.4)$ & $1(1.6)$ & $8(4.3)$ & $0(0)$ \\
\hline $\begin{array}{l}\text { New referral to } \\
\text { secondary care for } \\
\text { persistent symptoms in } \\
3 \text { years after diagnosis } \\
\text { of cholecystolithiasis, } \\
n(\%)\end{array}$ & $56(19.0)$ & $56(24.0)$ & $\mathrm{N} / \mathrm{A}$ & 41 (22.2) & 15 (31.3) \\
\hline Dept. of surgery & $12(4.1)$ & $12(5.2)$ & N/A & $9(4.9)$ & $3(6.3)$ \\
\hline $\begin{array}{l}\text { Dept. of } \\
\text { gastroenterology }\end{array}$ & $30(10.2)$ & 30 (12.9) & N/A & $22(11.9)$ & $8(16.7)$ \\
\hline
\end{tabular}

Continued 


\begin{tabular}{|c|c|c|c|c|c|}
\hline & \multirow[b]{2}{*}{$\begin{array}{l}\text { All patients } \\
(\mathrm{N}=294)\end{array}$} & \multirow[b]{2}{*}{$\begin{array}{l}\text { Referral } \\
(\mathrm{N}=233)\end{array}$} & \multirow[b]{2}{*}{$\begin{array}{l}\text { No referral } \\
(\mathrm{N}=61)\end{array}$} & \multicolumn{2}{|l|}{ Referral } \\
\hline & & & & $\begin{array}{l}\text { Cholecystectomy } \\
(\mathrm{N}=185)\end{array}$ & $\begin{array}{l}\text { No cholecystectomy } \\
(\mathrm{N}=48)\end{array}$ \\
\hline $\begin{array}{l}\text { Emergency } \\
\text { department }\end{array}$ & 7 (2.4) & 7 (3.0) & $\mathrm{N} / \mathrm{A}$ & $5(2.7)$ & $2(4.2)$ \\
\hline
\end{tabular}

*A significant difference $(p<0.05)$ was found between patients who did or did not receive a cholecystectomy. †Based on 137/294 patients.

$\ddagger$ A significant difference $(\mathrm{p}<0.05)$ was found between referred and not referred patients.

$\S$ Complaints recorded within 6 weeks of surgery were considered to be surgery related and were not scored.

$\mathrm{BMI}$, body mass index; GP, general practitioner; NA, not available.

did not require surgery over a 14-year period. ${ }^{1415}$ Another prospective cohort study by Berger $e t$ al in primary care patients with suspected cholecystolithiasis showed that neither biliary pain nor any other gastrointestinal complaint was related to cholecystolithiasis consistently. The authors concluded that before the diagnosis symptomatic cholecystolithiasis is made, other common gastrointestinal pathology (eg, reflux esophagitis and irritable bowel syndrome, should be excluded. ${ }^{16}$ In our study, $40 \%$ of patients consulted their GP with symptoms resulting in another abdominal-related diagnosis before the diagnosis cholecystolithiasis was set. Interestingly, this specific group of patients with a previous abdominal related diagnosis returned more often with persistent symptoms after referral. To aid clinicians to better select patients for cholecystectomy, we recently reported on an online decision tool. The variables included in this tool illustrate that patient characteristics, pain scores, surgical history and signs of functional gastrointestinal disorders are more the relevant factors to predict clinically relevant pain reduction after surgery. ${ }^{17}$

Cholecystectomy is indicated for complicated gallstone disease (eg, cholecystitis, biliary pancreatitis), while consensus among surgeons and gastroenterologists for the selection for cholecystectomy in uncomplicated gallstone disease is absent. ${ }^{18}$ Underlying gastrointestinal disorders such as dyspepsia, heartburn, regurgitation or constipation hamper the outcome of cholecystectomy. Therefore, we advise GPs to address these specific disorders and rule them out as a potential cause of abdominal pain. Although we are aware that functional disorders as obstipation, dyspepsia, or heartburn are sometimes difficult to differentiate from biliary pain, the results of this study may be of help in the process of informing the patient and shared decision making about referral and surgery. This advice is endorsed by the results of this study and the results of a recent study in secondary care in which the role of abdominal-related disorders was evaluated in patients with cholecystolithiasis. ${ }^{6}$ We showed indecisive outcomes after surgery in 400 patients with abdominal pain and gallstones, especially if irritable bowel syndrome or dyspepsia were present. Noticeably, our study found that over half of patients with cholecystolithiasis also received concomitant abdominal-related diagnoses, while this percentage in the general population is around $40 \%{ }^{19}$ A wait-and-see policy with an

Table 2 Comparison of patients who did or did not return to their GP for persistent abdominal-related diagnoses after referral

\begin{tabular}{|c|c|c|c|c|}
\hline & $\begin{array}{l}\text { Total } \\
(n=233)\end{array}$ & $\begin{array}{l}\text { Return to GP } \\
(n=129)\end{array}$ & $\begin{array}{l}\text { No return to GP } \\
(n=104)\end{array}$ & $P$ value \\
\hline Sex, female (\%) & $147(63.1)$ & $84(65.1)$ & $63(60.6)$ & 0.475 \\
\hline Age, mean (SD) & $58.3(13.8)$ & $57.9(13.8)$ & $58.9(14.1)$ & 0.207 \\
\hline BMI, mean (SD) & $29.8(6.1)$ & $30.2(6.4)$ & $29.2(5.7)$ & 0.387 \\
\hline $\begin{array}{l}\text { An abdominal-related diagnosis recorded before } \\
\text { cholecystolithiasis, } n(\%)\end{array}$ & $97(41.6)$ & $67(51.9)$ & $30(28.8)$ & $<0.001$ \\
\hline $\begin{array}{l}\text { No of consultations for abdominal-related diagnoses, } \\
\text { median (IQR) }\end{array}$ & $9(7.75)$ & $12(9)$ & $6(4)$ & $<0.001$ \\
\hline Before diagnosis of cholecystolithiasis & $3(3)$ & $3(3)$ & $2(2)$ & $<0.001$ \\
\hline After diagnosis of cholecystolithiasis & $6(6)$ & $8(6)$ & $4(3)$ & $<0.001$ \\
\hline Biliary colic, n (\%) & $144(61.8)$ & $72(55.8)$ & $72(69.2)$ & 0.036 \\
\hline Cholecystectomy, yes (\%) & 185 (79.4) & $97(75.2)$ & $88(84.6)$ & 0.077 \\
\hline
\end{tabular}

BMI, body mass index; GP, general practitioner. 
interval of a few weeks is preferred, as this policy generally discriminates more adequately between biliary and nonbiliary pain relative to additional diagnostic tests or an invasive gastrointestinal endoscopy.

The strength of the present multipractice study is the 3-year time interval before and after the diagnosis cholecystolithiasis. This interval optimised the assessment of the diagnostic pathway, medication prescription and referral pattern in this patient group. The analysis of EMRs of 294 patients provided real-life information on healthcare utilisation and type of received treatment in secondary care facilities. We acknowledge this study comes with some limitations. First, data were collected retrospectively, which may lead to information bias. Second, registry data laboratory diagnostics and prescribed medication may not only relate to the diagnosis cholecystolithiasis and detailed hospital data were not available. Finally, even though the EMRs ensure complete information, differentiation between different diagnoses may not always be accurate. GPs may record the diagnosis cholecystolithiasis without the presence of typical complaints. The analysis of the subset showed this may have applied to the registry data, as a biliary colic was only reported in $57 \%$ of patients. This illustrates the complexity of diagnosing patients with abdominal-related symptoms in primary care.

\section{Implications for practice}

This study found that patients with cholecystolithiasis are often referred to a hospital while half of these patients return with persistent abdominal symptoms. The high prevalence of abdominal-related diagnoses before the diagnosis of cholecystolithiasis in patients with repeat visits stresses the fact that GPs should be precarious when referring patients with non-typical complaints. Shared decision-making before referral is necessary, especially in patients with another initial abdominal-related diagnosis. It is pivotal to manage patients' expectations on the outcomes of cholecystectomy early in the referral chain, making a clear distinction between the beneficial effect on biliary colic and questionable effect on non-biliary abdominal pain. This study adds to the growing awareness that there is no consensus within our medical community on the indication for cholecystectomy in patients with uncomplicated cholecystolithiasis and abdominal pain. GPs, gastroenterologists and surgeons are cordially invited to discuss the present findings and to collaborate on optimising criteria for diagnostics, referral and treatment of this large group of patients.

\section{Twitter Henk J Schers @hjsch64}

Acknowledgements We would like to thank the Practice Based Research Network (PBRN) Radboudumc Family Medicine Network for their support in the acquisition of the data and their support in the contact with the general practices.

Contributors All authors made substantial contributions to the conception and design of this study. All authors edited the manuscript and approved the final version of the manuscript. Conception or design of the study: HJS and PRdR. Data collection: FMT and LDD. Data analysis and interpretation: FMT, LDD, HJS and PRdR. Drafting the manuscript: FMT, LDD, HJS and PRdR. Critical revision of the article: BB, JPHD and CJHMvL. PRdR is guarantor.
Funding The authors have not declared a specific grant for this research from any funding agency in the public, commercial or not-for-profit sectors.

Competing interests None declared.

Patient consent for publication Not applicable.

Ethics approval Ethics approval was provided by the Radboudumc Medical Ethics Review Committee (number 2020-6871).

Provenance and peer review Not commissioned; externally peer reviewed.

Data availability statement Data are available on reasonable request.

Supplemental material This content has been supplied by the author(s). It has not been vetted by BMJ Publishing Group Limited (BMJ) and may not have been peer-reviewed. Any opinions or recommendations discussed are solely those of the author(s) and are not endorsed by BMJ. BMJ disclaims all liability and responsibility arising from any reliance placed on the content. Where the content includes any translated material, BMJ does not warrant the accuracy and reliability of the translations (including but not limited to local regulations, clinical guidelines, terminology, drug names and drug dosages), and is not responsible for any error and/or omissions arising from translation and adaptation or otherwise.

Open access This is an open access article distributed in accordance with the Creative Commons Attribution Non Commercial (CC BY-NC 4.0) license, which permits others to distribute, remix, adapt, build upon this work non-commercially, and license their derivative works on different terms, provided the original work is properly cited, appropriate credit is given, any changes made indicated, and the use is non-commercial. See: http://creativecommons.org/licenses/by-nc/4.0/.

\section{ORCID iDs}

Floris Martijn Thunnissen http://orcid.org/0000-0002-1012-7991

Henk J Schers http://orcid.org/0000-0002-9362-9451

\section{REFERENCES}

1 Health Care Utilisation. Operation for economic Co-operations and development, 2020. Available: https://stats.oecd.org/index.aspx? queryid $=30167$

2 Nederlandse Vereniging voor Heelkunde (NVvH). Evidence-Based guideline: diagnostic and treatment of gallstones. Available: https:// richtlijnendatabase.nl/richtlijn/galsteenlijden [Accessed Feb 2020].

3 Lammert F, Gurusamy K, Ko CW, et al. Gallstones. Nat Rev Dis Primers 2016;2:16024.

4 Berger MY, van der Velden JJ, Lijmer JG, et al. Abdominal symptoms: do they predict gallstones? A systematic review. Scand J Gastroenterol 2000;35:70-6.

5 van Dijk AH, Wennmacker SZ, de Reuver PR, et al. Restrictive strategy versus usual care for cholecystectomy in patients with gallstones and abdominal pain (secure): a multicentre, randomised, parallel-arm, non-inferiority trial. Lancet 2019;393:2322-30.

6 de Jong JJ, Latenstein CSS, Boerma D. Functional Dyspepsia and Irritable Bowel Syndrome are Highly Prevalent in Patients With Gallstones and are Negatively Associated With Outcomes After Cholecystectomy: A Prospective, Multicentre, Observational Study (PERFECT - Trial). Ann Surg 2020. [Epub ahead of print: 01 Sep 2020].

7 von Elm E, Altman DG, Egger M, et al. The strengthening the reporting of observational studies in epidemiology (STROBE) statement: guidelines for reporting observational studies. J Clin Epidemiol 2008;61:344-9.

8 European Association for the Study of the Liver (EASL). Electronic address: easloffice@easloffice.eu. EASL clinical practice guidelines on the prevention, diagnosis and treatment of gallstones. $J$ Hepatol 2016;65:146-81.

9 Vetrhus M, Søreide O, Eide GE, et al. Pain and quality of life in patients with symptomatic, non-complicated gallbladder stones: results of a randomized controlled trial. Scand J Gastroenterol 2004;39:270-6.

10 Lamberts MP, Lugtenberg M, Rovers MM, et al. Persistent and de novo symptoms after cholecystectomy: a systematic review of cholecystectomy effectiveness. Surg Endosc 2013;27:709-18.

11 Lamberts MP, Den Oudsten BL, Gerritsen JJGM, et al. Prospective multicentre cohort study of patient-reported outcomes after cholecystectomy for uncomplicated symptomatic cholecystolithiasis. Br J Surg 2015;102:1402-9.

12 Latenstein CSS, de Jong JJ, Eppink JJ, et al. Prevalence of dyspepsia in patients with cholecystolithiasis: a systematic review and meta-analysis. Eur J Gastroenterol Hepatol 2019;31:928-34. 
13 National Institute for Health Research. A randomised controlled trial comparing the clinical effectiveness and cost-effectiveness of laparoscopic cholecystectomy compared with observation/ conservative management for preventing recurrent symptoms and complications in adults with uncomplicated symptomatic gallstones (C-Gall), 2016. Available: https://www.journalslibrary.nihr.ac.uk/ programmes/hta/1419271\#/ [Accessed 21 Dec 2020].

14 Schmidt M, Søndenaa K, Vetrhus M, et al. Long-Term follow-up of a randomized controlled trial of observation versus surgery for acute cholecystitis: non-operative management is an option in some patients. Scand J Gastroenterol 2011;46:1257-62.

15 Schmidt M, Søndenaa K, Vetrhus M, et al. A randomized controlled study of uncomplicated gallstone disease with a 14-year followup showed that operation was the preferred treatment. Dig Surg 2011;28:270-6.
16 Berger MY, Olde Hartman TC, van der Velden JJIM, et al. Is biliary pain exclusively related to gallbladder stones? A controlled prospective study. Br J Gen Pract 2004;54:574-9.

17 Latenstein CSS, Hannink G, van der Bilt JDW, et al. A clinical decision tool for selection of patients with symptomatic cholelithiasis for cholecystectomy based on reduction of pain and a Pain-Free state following surgery. JAMA Surg 2021;156:e213706.

18 Lamberts MP. Indications of cholecystectomy in gallstone disease. Curr Opin Gastroenterol 2018;34:97-102.

19 Sperber AD, Bangdiwala SI, Drossman DA, et al. Worldwide prevalence and burden of functional gastrointestinal disorders, results of Rome Foundation global study. Gastroenterology 2021;160:99-114. 